\title{
Educação Profissional em Turismo. Cria-se Mercado pela Formação?
}

\author{
Are Jobs in Tourism Created by Professional Education?
}

Edegar Luis Tomazoni ${ }^{1}$

\begin{abstract}
RESUMO: Um dos enfoques da ideologia do turismoé a sua potencialidade de geração de empregos e renda. Para alguns analistas céticos, essa ideologia seria, entretanto, mais mito do que realidade. Uma das principais estratégias para tornar o turismo uma alternativa real de desenvolvimento, no momento em que o desemprego é um dos problemas que mais afligem o Brasil, seria a formação profissional que impulsionaria a criação de oportunidades de mercado. Para analisar a tese da geração da empregabilidade em turismo, contextualiza-se o estudo nas principais teorias socioeconômicas e aplicam-se os modelos de qualificação e competência para o entendimento da complexa relação entre formação profissional no setor e a transformação do mercado de trabalho.
\end{abstract}

PALAVRAS-CHAVE: turismo; formação profissional; teorias; empregabilidade; competência; qualificação.

ABSTRACT: One of the issues of the tourism ideology is its potential in
creating job opportunities and revenue. To some sceptic analysts, this ideo-
logy is more myth than reality. One of the main strategies to make tourism a
real alternative to development in a time when unemployment is one of the
most disturbing problems of Brazil would be the professional formation to
boost the creation of market opportunities. To analyse the theses of tourism
employment, this study is based in some of the social and economic theories,

1. Doutor em Ciências da Comunicação, área de concentração Relações Públicas, Propaganda e Turismo, linha de pesquisa Turismo e Lazer, pela Universidade de São Paulo; mestre em Turismo, linha de pesquisa Organização de Eventos, pela Universidade de Caxias do Sul - UCS; pós-graduado em Desenvolvimento Empresarial pela Universidade Federal do Rio Grande do Sul - UFRGS; graduado em Engenharia Química pela Pontifícia Universidade Católica do Rio Grande do Sul - PUCRS. Professor e Pesquisador do Programa de Pós-graduação PPGTUR (Mestrado Acadêmico de Turismo) e professor dos departamentos de Administração e de Turismo e Hotelaria da UCS. Contato: rua Governador Roberto Silveira, 1268/201 - 95032-710 - Caxias do Sul - RS; e-mail: edegarlt@terra.com.br. 
and the models of qualification and competence are applied to understand the complex relation between the professional formation in the sector and the transformation of the work market.

KEYWORD: tourism; professional education; theories; employment opportunities; competence; qualification.

\section{Introdução}

Os métodos de estudos, de pesquisas e de análises, de acordo com as diferentes visões das teorias marxiana e capitalista, e suas implicações na empregabilidade, aplicam-se de forma abrangente às atividades econômicas, por mais que elas se diferenciem umas das outras. O estudo do turismo se insere, portanto, neste contexto teórico e está submetido aos mesmos fatores econômicos e às políticas de educação, formação e inserção profissional que as demais atividades, resguardadas, porém, as suas características e peculiaridades socioculturais.

O estudo da empregabilidade em turismo, como atividade econômica, enfoca o papel do indivíduo, na sociedade do trabalho, em relação à sociedade de consumo do lazer como produto. $\mathrm{Na}$ economia capitalista, além da apropriação da força de trabalho pelas empresas para a mais-valia do capital, o trabalhador passou a vender também o seu tempo livre e a destinar o resultado da sua luta diária pela sobrevivência - o salário - para a compra ou o consumo de lazer. A economia pós-industrial continua impondo regras à oferta e à procura de mão-de-obra no mercado de trabalho, e, na sociedade capitalista de consumo, as organizações de produção de serviços de lazer competem cada vez mais pela conquista do trabalhador também como cliente.

É em meio a um cenário de contrastantes realidades, em que alguns têm acesso ao desfrute do lazer, como forma de aproveitamento do tempo livre, enquanto outros sequer têm acesso ao mercado de trabalho e à renda para poderem consumir o lazer como produto, que se desenvolve o turismo como atividade que "industrializa" o ócio.

Para Thurow (1996: 29):

[...] os romanos condenavam os valores comerciais 'vulgares e ignóbeis' que estão hoje no coração do capitalismo. Um homem livre não podia trabalhar em troca de um salário, uma vez que isto significava estar sujeito às ordens de outro homem e equivalia a ser escravo. Nas palavras de Cícero, o trabalho assalariado era sórdido e indigno de um homem livre.

Se esta mesma idéia vigorasse atualmente, o que se diria, então, de uma pessoa que exerce trabalho assalariado em atividades ligadas ao lazer? Para que alguns desfrutem dos prazeres do lazer e do turismo, é necessário que outros trabalhem na execução de tarefas, em uma ampla gama de segmentos de atividades que abrange, desde as construções de meios de hospedagem até a oferta de serviços de recreação, entretenimento e animação cultural. Este tipo de trabalho poderia ser considerado, então, na sociedade da Roma antiga, uma forma de extrema e humilhante escravidão.

Nos dias atuais, entretanto:

[...] em termos marxistas, o que os assalariados vendem não é seu trabalho, mas a força de trabalho. Como proprietários de mercadorias, os trabalhadores têm a liberdade para vender ou não sua força de trabalho, mas esta liberdade é mais formal que real, já que precisam trabalhar, ou, do contrário, morreriam de fome. Essa proposição poderia explicar-se melhor tendo em conta as diferenças existentes nas condições da oferta de trabalho. Assim, pois, segundo Marx, a relação entre o trabalhador e o patrão é uma relação de poder, em que a posição do trabalho depende, de uma maneira fundamental, do fato de que os assalariados não têm outra opção que a venda de sua força de trabalho a um salário dado. E, tão logo os trabalhadores começam a trabalhar, deixam de possuir seu trabalho, pois este se submete ao controle do capitalista (Villa, 1990).

\section{Para De Masi (2000):}

[...] o futuro será feito, sobretudo, de tempo sem trabalho. Entretanto, a escola e a família só preparam para o trabalho, não preparam para o tempo livre. Muito pouco se ensina como escolher um filme, como escolher uma ópera, o que ouvir nem como ouvir música. Ao se aposentar, aos 60 anos, a pessoa ainda vai viver 20 anos sem saber o que fazer. Viverá uma vida psiquicamente forte, mas fisicamente perdida. No futuro, será impossível distinguir estudo e trabalho de tempo livre, por causa das próprias atividades deste futuro. Atualmente, as pessoas são 'escravas' do salário. A tecnologia industrial libertou do cansaço físico e de toda uma série de trabalhos perigosos e nocivos. É hora de se libertar do cansaço intelectual, do trabalho residual. $O$ trabalho não é o único salvo-conduto para ganhar um salário. Por que um estudante de 20 anos ganha um salário para trabalhar em um banco e não pode ganhar o mesmo salário para continuar apenas estudando na universidade? Em muitos edifícios, há elevadores e jovens trabalhando como ascensoristas. São totalmente inúteis. Estão fechados numa caixa, mas se não sobem e não descem apertando o botão, não recebem o salário. Pode-se dar a estes jovens o salário e dizer: 'vá para a escola' ou 'vá se divertir'. Criou-se uma escola na qual quem não trabalha ou não finge trabalhar não tem direito de viver. É uma incoerência impressionante. 


\section{Qualificação, segmentação e flexibilidade do mercado} de trabalho

É na contextualização capitalista que se situa a análise da situação do trabalhador no setor de turismo, a exemplo de outros setores da economia. Os atributos do trabalhador, como qualificação e competência, poderiam ser definidos como mercadorias das quais o mercado capitalista se apropria para viabilizar seus objetivos de produção e de lucro. O trabalhador vende sua força de trabalho e seu tempo sob um processo de negociação que pode ser competitivo ou institucionalizado, dependendo do grau de envolvimento, interferência e controle das diversas organizações da sociedade, como governos e sindicatos. Uma das formas de regulação dessa negociação de compra e venda é o salário, que remunera o trabalhador e cujo valor pode variar de acordo com a realidade de cada setor de atividade econômica.

Na prática, não se verificou o apregoado equilíbrio automático entre produção e consumo, a decantada harmonia entre os interesses do indivíduo e os da sociedade. Pelo contrário, os grandes conflitos sociais colocaram em evidência os grandes defeitos do capitalismo, coexistindo com seus aspectos positivos. Considerando o predomínio do sistema capitalista e o fato de o modelo socialista ainda não ter sido plenamente praticado, as atenções devem concentrar-se no modelo capitalista, porque é o único que dispõe de dados para análise do turismo, levando-se em conta que esta atividade teve origem e predomina neste sistema (Beni, 2001).

Ribeiro situou a qualificação no trabalho capitalista, explicando que o assalariado está subordinado, sob o controle, o mando, a supervisão e a direção do capitalista; ele já não faz o seu trabalho, senão o trabalho que lhe cabe na valorização do capital. A idéia geral da qualificação do trabalhador está em um terreno dirigido por forças ambíguas, conflitivas, cambiantes e contraditórias, postas a serviço da valorização do capital.

Para Oliveira (1998), o capital humano é um estoque de conhecimentos que os indivíduos podem optar por adquirir, mediante um investimento em educação/ formação, saúde e mobilidade. A questão da qualificação, na perspectiva marxiana, é colocada, de certo modo, de maneira inversa à teoria do capital humano, e o que é valorizado é o saber-fazer associado à experiência profissional. Na teoria da segmentação, a empresa é um agente ativo de transformação de mão-de-obra e de produção de qualificações específicas, resultando disto o processo de socialização - complexa relação entre o sistema de ensino/formação e o sistema produtivo. $\mathrm{Na}$ teoria da segmentação, o mercado é concebido como um conjunto de cadeias de mobilidade, interna e externa, e sujeito a regras de concorrência. $\mathrm{Na}$ análise da teoria da regulação, há um mercado estratificado, e não diferentes mercados. Essa tese se fundamenta no conceito de relação salarial, que, segundo Boyer (1981), é o conjunto de condições jurídicas e institucionais que regem a utilização e a reprodução do trabalho assalariado.

Uma das peculiaridades da cadeia produtiva do turismo é a conjugação de uma gama de organizações, cujos envolvimentos ultrapassam as fronteiras do próprio setor, gerando implicações em outros setores da economia. As organizações são coletividades de indivíduos, especializadas na produção de bens e serviços, e o turismo se inscreve no contexto das organizações de serviços. A teoria da segmentação poderia se aplicar ao turismo mais do que a outros setores, pois cada segmento - hotelaria, gastronomia, transportes, lazer cultural, compras -, forma um conjunto de cadeias de mobilidade. Os trabalhadores em turismo, pela diversidade de oportunidades, de envolvimentos e de contatos, teriam condições especiais de adquirir conhecimentos, aumentando o capital humano.

Para Villa (1990), nem a demanda nem a oferta de trabalho dependem dos salários: a demanda de trabalho está relacionada com o nível de produção das empresas e a oferta de trabalho está determinada, em geral, por fatores demográficos e sociais. Em razão destes problemas, modificou-se a definição econômica e a percepção do mercado de trabalho. Introduziu-se um novo conjunto de categorias, como mercado dual de trabalho, primário/secundário, interno/externo, núcleo/periferia/irregular, e um novo conjunto de conceitos, como estratificação, internalização e segmentação. Propuseram-se diferentes hipóteses para explicar a persistência de trabalhadores desfavorecidos em grupos específicos. A idéia básica que substitui este novo enfoque é que o mercado de trabalho parece descrever-se melhor em função de uma série de segmentos em que já não se supõe que o processo de determinação dos salários e a mobilidade do trabalho estejam estreitamente conectados.

A empregabilidade em turismo pode ser mais complexa do que em outros setores, tanto pelas suscetibilidades aos fatores sociais e demográficos, aos quais esta atividade econômica está submetida, quanto em razão da diversidade de segmentos que a compõem. Esta situação implica que cada segmento seja analisado de acordo com critérios próprios e específicos, tendo em vista entender os processos de mobilidade entre as empresas de um mesmo segmento e entre segmentos diferentes. Assim, por exemplo, a hotelaria apresenta características salariais de empregabilidade e de mobilidade que se diferenciam em relação às características dos segmentos de agências de viagens, de organização de eventos e de comercialização de produtos artesanais.

O profissional do turismo, no Brasil, é identificado como turismólogo, de acordo com a legislação vigente. Têm direito ao exercício da profissão de turis- 
mólogo os formados por cursos de níveis médio, técnico e superior, e, também, pessoas que comprovem experiência no mercado de trabalho do setor. Esse perfil, apesar de uma idéia de valorização e de padronização, é multiabrangente e de difícil conceituação, tanto em teoria quanto na prática, mas pode contribuir para analisar as questões de intra e intermobilidade profissional e de implicações nas variações salariais do turismo.

Para Singer (1998), os estudos da teoria da segmentação confirmam que a flexibilidade externa procura traduzir para a gestão do pessoal o que representa o método just in time na gestão de estoques. Trata-se de evitar estoques de mãode-obra sem utilização imediata. A flexibilidade é mais vantajosa para a empresa, pois ela deixa de pagar o tempo de ociosidade. A teoria da segmentação divide o mercado de trabalho em dois segmentos: o primário e o secundário. No segmento primário, os trabalhadores são mais bem pagos, têm estabilidade, perspectiva de carreira, segurança, boa remuneração e regulamentação. No segmento secundário, a situação é oposta: os empregos são instáveis, inseguros, precários e sem direitos trabalhistas.

Pela teoria da segmentação de Singer, a flexibilidade é mais vantajosa para a empresa, pois ela não assume o pagamento do tempo de ociosidade. Pelas características como sazonalidade e heterogeneidade da demanda e variedade de ofertas, muitos dos tipos de trabalho gerados pelo turismo se inserem no segmento secundário da teoria da segmentação, pois são instáveis, precários e inseguros. No Brasil, o turismo é uma atividade capitalista recente, sendo que a maioria dos segmentos abrangidos pelo setor ainda não atingiu a maturidade, situação que afeta e prejudica as formas de regulação salarial.

Não se propõe, neste artigo, apresentar respostas para muitas dúvidas, mas problematizar, no setor de turismo, a relação entre educação para formação profissional e inserção no mercado de trabalho, definida como processo de socialização. No entanto, a partir das idéias dos autores referidos, poder-se-iam sugerir alguns temas para serem pesquisados nesta área, como os seguintes: (1) a aplicação da teoria da segmentação às situações de assalariamento e precarização do trabalho em turismo, em razão, por exemplo, da sazonalidade; (2) qual deveria ser o grau de qualificação do trabalhador para o turismo, submetido às forças ambíguas, conflitivas, cambiantes e contraditórias do capital; (3) como se dá, efetivamente, o processo de socialização, na complexa relação entre o sistema de ensino/formação e o sistema produtivo em turismo.

\section{Contextualização econômica do turismo}

O paradoxo da expansão dos serviços e do aumento da exclusão social

A sociedade pós-industrial está preocupada com a qualidade de vida, medida por serviços, tais como saúde, educação e lazer. A figura central é o profissional, porque, mais do que energia ou força física, a informação é o recurso-chave, potencializada pela comunicação eletrônica em tempo real (Castels, 1999). A transformação de uma sociedade ocorre em razão da automação e do consumo em massa. Cada vez mais incapazes de competir com base nas vantagens dos produtos, as economias ocidentais estão sendo transformadas em economias de serviços. É uma encruzilhada histórica, em que a era da orientação para o consumidor chegou até mesmo para setores que jamais foram encarados como atividades específicas de serviços (Carlzon, 1994).

Instituições e indivíduos compram serviços, em vez de gastar tempo realizando atividades por conta própria. Gastos com despreocupação levaram a uma proliferação de serviços pessoais, principalmente no setor do lazer. Houve um aumento na variedade e na diversidade de serviços oferecidos. Em termos econômicos, em 1980, a indústria de serviços foi responsável por 58\% do Produto Interno Bruto (PIB) mundial, e a atividade internacional de serviços foi responsável por $20 \%$ de todo o comércio mundial. Em 1992, o seu desempenho havia quase triplicado, alcançando US $\$ 1.000$ bilhões. As indústrias de serviços não só aumentaram de tamanho, como também absorveram todos os postos de trabalho dispensados ao longo dos anos por setores tradicionais, como agricultura, mineração e atividades manufatureiras. O setor de serviçosé, atualmente, responsável por mais de 75\% do total de empregos nos Estados Unidos. Trata-se de uma sociedade pós-industrial, ou de uma sociedade de serviços (Fitzsimmons, 2000). A indústria de serviços emprega 133 milhões de pessoas, ou 60\% da força de trabalho na União Européia, enquanto o emprego industrial diminuiu constantemente para $32 \%$ (Bateson \& Hoffman, 2001).

De acordo com Pochmann (1999), de 1989 a 1995, o setor terciário no Brasil apresentou um aumento de $69 \%$ para $73,7 \%$ nas ocupações de trabalho. $O$ segmento não-organizado aumentou de $22,6 \%$ para $30,1 \%$, com maior número de postos ( 9 em cada 10). Após 1980, por razões endógenas e também macroeconômicas, houve uma desestruturação do mercado de trabalho, com expansão do desassalariamento, gerando segmentos não-organizados e desemprego, em razão do abandono do projeto de industrialização. O segmento não-organizado registrou variações anuais de emprego de 5,8\%, nos anos de 1985-1990, e de 
6,4\%, de 1990 a 1996. Os setores com mais possibilidade de readmissão estão na construção civil, no comércio varejista e nos serviços de alojamento, alimentação e administração de imóveis. Os empregos são insuficientes, e em geral precários, nos setores de serviços básicos (limpeza, segurança, alimentação). Verifica-se, portanto, que, enquanto o setor de serviços cresce, diminui a oferta de empregos estáveis em diversas áreas essenciais.

Para Pochmann (2001):

[...] o ciclo de acumulação de capital e a onda de inovação causaram uma profunda desigualdade no acesso ao avanço tecnológico, sendo que $20 \%$ das pessoas nos países ricos têm acesso a computador, enquanto apenas de $2 \%$ a 7\%, nos países periféricos. O clube dos mais ricos do mundo representa apenas $0,1 \%$ da população, sendo apenas 140 pessoas no Brasil com renda anual de um milhão de dólares. Em meio a este contexto de desigualdades e excessiva concentração de renda, a irradiação da Internet favoreceu a expansão de serviços de lazer e turismo. Setores de saúde, educação e entretenimento, desporto, cultura e lazer significavam 28\% dos empregos nos Estados Unidos e 24\%, na França, de 1988 a 1998. No Brasil, a cada cem vagas geradas de 1989 a 1999, duas eram de garçons e cozinheiros. Nos anos 90, o desemprego para pessoas com mais de oito anos de instrução subiu $620 \%$ e, para pessoas com menos de um ano de instrução, 189\%, situação que abrange também o setor de serviços.

Ainda segundo Pochmann, "sem o encadeamento de arranjos entre empresas, universidades e governos para a inovação tecnológica, o Brasil seguirá na contramão da história".

É o setor de serviços, que, a cada dia, se expande e se consolida como um setor econômico de expressivas cifras financeiras e de significativo aproveitamento de capacidades e recursos humanos, que se movimentam as atividades do turismo. Apesar da morosidade da conjuntura econômica atual, a OMT - Organização Mundial do Turismo diz que os profissionais do setor mostram-se otimistas. A previsão é de que, daqui a 15 anos, o número de turistas deverá duplicar, enquanto as receitas deverão quadruplicar. O fato de que 100 milhões de chineses deverão viajar pelo mundo afora é um exemplo que ilustra esta expectativa. Apesar de tudo, a crise do setor não é estrutural. De fato, certos lugares de destino, considerados como áreas de risco, têm sido evitados pelos consumidores. Mas as companhias de viagens se adaptam, propondo destinos mais próximos (OMT, 2004). Existe, portanto, a expectativa de que, em âmbito global, o turismo se constitua como uma atividade promissora em geração de oportunidades de emprego.

\section{Desenvolvimento do turismo: empregabilidade?}

A conceituação de desenvolvimento é baseada em vários aspectos da vida humana. Um dos critérios mais utilizados para a fundamentação conceitual do desenvolvimento é a renda. Este, entretanto, é apenas um dos parâmetros para analisar a situação de inclusão de um indivíduo na sociedade. O desenvolvimento está relacionado a situações como expectativa de vida ao nascer, educação e, também, a uma dimensão psicológica e cultural que diz respeito à inclusão social. O IDH - Índice de Desenvolvimento Humano, adotado pela ONU - Organização das Nações Unidas, se fundamenta, portanto, na renda per capita, na expectativa de vida e na educação. Desenvolvimento humano não significa crescimento econômico, isto é, o fato de haver crescimento econômico não é condição suficiente para o desenvolvimento humano. Um país pode apresentar índices elevados de crescimento econômico, mas ser injusto na distribuição da renda e no acesso da população à educação e ao mercado de trabalho. Para que haja desenvolvimento humano, é necessário haver distribuição dos resultados gerados pelo crescimento econômico. Em razão disto, é importante analisar as efetivas contribuições do turismo para o desenvolvimento e identificar as estratégias que viabilizem a sua implementação.

As definições de turismo, por vários autores e pesquisadores internacionais, sintetizam e traduzem o sentido de amplitude, abrangência e envolvimentos deste setor, definido com um sistema que se segmenta em diversos subsistemas. A partir das definições, é possível expandir as reflexões e análises para o entendimento das implicações do turismo como um amplo mercado, um sistema de atividades, cujas potencialidades de geração e distribuição de riqueza e renda podem efetivamente contribuir com o desenvolvimento. É importante problematizar estas questões, tendo em vista questionar-se a tese de que investimentos na área, especialmente, na formação profissional, são efetivamente estratégias de desenvolvimento e inserção de trabalhadores no mercado de trabalho.

Por um lado, uma das principais razões destacadas pela OMT para a expansão do mercado do turismo é a qualificação profissional, que contribuiu com a melhoria da qualidade dos serviços. Por outro, a falta de profissionais qualificados para atuação no setor é um dos fatores que dificultam o desenvolvimento do turismo. Quanto à empregabilidade dos profissionais formados, em níveis médio, técnico e superior, ainda não há pesquisa suficiente na área que possibilite mensurar a efetiva absorção de egressos das instituições de ensino pelo mercado de trabalho, a não ser alguns estudos de caso.

Um grupo de pesquisadores (Gândara, Paixão \& Luque, 2003) analisou, em 2002, a situação de 45 hotéis de Curitiba - PR, mediante entrevistas com os 
gerentes. Algumas das principais constatações foram as seguintes: (1) os gerentes dos hotéis dizem que a faculdade fantasia a carreira e ilude o aluno, de modo que eles propõem que o ensino seja mais voltado à realidade; (2) não existe um sistema de remuneração por competência, apenas comissões de 10\%; (3) 53,33\% dos gerentes consideram o ensino superior importante; $40 \%$ têm, entretanto, preferência pelos cursos técnicos e $56,67 \%$ preferem os cursos profissionalizantes; (4) as aptidões consideradas mais importantes são personalidade (50\%), motoras e apresentação pessoal (27\%); (5) as aptidões consideradas menos importantes são as intelectuais e analíticas (23\%); (6) a habilidade considerada mais importante é $\mathrm{o}$ atendimento a pessoas (52\%).

Para Urry (2000):

[...] uma das perguntas que devem ser formuladas sobre o desenvolvimento do turismo é desenvolvimento para quem? Muitas das facilidades que resultam do crescimento do turismo como atividade econômica - aeroportos, campos de golfe, hotéis de luxo e outros - são de poucos benefícios para a massa da população indigente. A maior parte da riqueza que é gerada é assimetricamente distribuída e a maior parte da população dos países em desenvolvimento participa de uma pequena parcela dos benefícios. A maioria dos empregos gerados nos serviços relacionados ao turismo é relativamente de baixa capacitação e pode reproduzir o servilismo característico dos regimes coloniais. Deve-se perguntar, entretanto, se muitos países em desenvolvimento têm outras alternativas ao turismo como uma estratégia de desenvolvimento.

\section{Krippendorf (1989) argumentou que:}

[...] o advento do turismo transformou a bela virtude humana da hospitalidade espontânea e gratuita num 'ganha-pão' e numa profissão. Mas, nesta grande 'indústria' que éo turismo, é evidente que o que prevalece é a escala de valores e dos promotores. $O$ turismo penetra, por exemplo, em regiōes rurais, onde as condiçōes de vida são piores e o nível de educação dos habitantes é, em geral, mais baixo que nas cidades. No setor turístico, a maioria dos empregos não tem nada de atraente. As condiçōes de trabalho são rigorosas: horas extras, horários irregulares, sobrecarga de acordo com a estação do ano e comprometimento pessoal em favor do cliente. Os salários são inferiores à média. As opçōes profissionais e as possibilidades de carreira são restritas. Muitas atividades não são qualificadas e são socialmente desfavorecidas. Quem domina na relação de forças é quem fornece o capital. Para obter vantagens da fortuna que o turismo proporciona, os nativos vendem o trabalho e o solo a preços baixos. Enquanto não se tornarem 'destinos' famosos que todos disputem, eles vão aceitar os preços que são propostos. Trata-se do reino desta lei implacável da oferta e da procura.
É interessante constatar que Molina (2003), um dos principais autores do turismo internacional, analisou a formação e o novo perfil profissional necessário para o setor, aplicando o conceito do modelo de competência. Para Molina (2003):

[...] o turismo requer um novo perfil na força de trabalho, uma nova geração de trabalhadores. No setor turístico, a maioria dos empregos - de todos os níveis - formou-se no cotidiano de trabalho e, portanto, carece de recursos teóricos e de uma cultura de gestão adequada, em face da clara necessidade de ampliar conhecimentos por meio de novos padrōes de educação, em que a sala de aula seja um cenário a mais, não sendo sequer o mais significativo. A educação e a capacitação para as empresas pós-turísticas provêm de outros parâmetros totalmente distintos. $\mathrm{O}$ conceito de multiprocesso transforma, de maneira radical, a idéia de hierarquia, que evolui de um conceito de imobilidade e rigidez para um conceito de alta mobilidade e flexibilidade. É uma nova cultura de trabalho, de produção e de prestação de serviços, na qual o conjunto de serviços se expressa como rede, com especificaçōes e volumes diversos que representam a elasticidade do sistema de produção e das habilidades do trabalhador. A gestão das empresas e instituições de sistemas com habilidades multitarefa conta com executivos, gerentes e pessoal operativo que apresentem competências: (1) básicas - fundamentais para qualquer trabalho ou profissão (operação de computadores e cultura organizacional); (2) diferenciadas - estabelecem uma diferença entre uma profissão e outra, a profissão adquire legitimidade social por envolver saberes exclusivos.

\section{A relação entre educação e inserção profissional em turismo}

As comparações entre o modelo de qualificação e o modelo de competência, a partir de uma ampla contextualização histórica e socioeconômica, proporcionam a identificação de inquietantes questões sobre a relação entre a formação profissional e o mercado de trabalho. Em síntese, constata-se que há muitos desafios, especialmente no que se refere à pesquisa, tendo em vista, exatamente, identificar qual o papel da educação profissional e da educação escolar para o funcionamento e a construção de mercados de trabalho. A educação escolar estaria mais relacionada ao modelo de qualificação, e a educação profissional, ao modelo de competência, ao mesmo tempo em que a transição da economia do sistema taylorista-fordista para o modelo de produção flexível impôs uma profunda ressignificação dos métodos de ensino-aprendizagem. Uma das constatações seria que um diálogo - um intercâmbio dinâmico entre a escola e o mercado (representado pelas organizações de emprego e trabalho) - poderia contribuir para a solução de dúvidas e 
angústias da sociedade atual, principalmente no tocante à inserção profissional. A escola defronta-se com o dilema de ter que considerar a importância das empresas como fontes de competência, como atributos de experiências adquiridas, ao mesmo tempo em que as empresas e o mercado de trabalho poderiam ter na escola uma parceria relevante para a solução dos problemas que se originam da exclusão dos meios de sobrevivência, perpassando as dimensões pessoais ou subjetivas do indivíduo (social-afetivo e mercadológico-profissional).

Para Moesch (2000), uma das hipóteses sobre a formação de competências ressalta o saber turístico como fazer-saber. A passagem do fazer-saber para o saber-fazer, no campo turístico, impõe às instituições de ensino o aprofundamento dos conhecimentos perpassados por seus currículos. Quais as categorias, o eixo norteador, as temáticas expressas pelas concepções teóricas que sustentam o ato de ensinar? Quais os métodos? É possível uma análise interdisciplinar? Qual o objetivo de ensinar nos meios acadêmicos, formar competências ou ideais?

Para Deluiz (2001), no modelo das competências, importam não só os saberes disciplinares escolares, mas as capacidades de mobilizá-los para resolver problemas e enfrentar imprevistos. Assumem extrema relevância os componentes não-organizados da formação - qualificações tácitas ou sociais e a subjetividade do trabalhador. O modelo das competências relaciona-se ao controle, à formação, à avaliação pelas exigências do padrão capitalista flexível ou toyotista - competitividade, agilidade, produtividade. Como aspectos positivos, identificam-se os seguintes: maior escolaridade, multiqualificação e polivalência, trabalho em equipe; e, como aspectos negativos, intensificação do trabalho, deslocamento e desqualificação profissional.

Para Stroobants (1997), competências se enriquecem com as aptidões dos saberes técnicos: saber ser, saberes sociais, capacidade de se comunicar, representações. Savoir-faire que se adquire no local de trabalho. Constatar que as competências no trabalho são mais importantes do que se imaginava impõe uma reviravolta metodológica que mostra que as competências reais são uma construção social. Competências mais eficazes do que saberes formais são conhecimentos tácitos adquiridos no local de trabalho. As competências que desafiam a formalização não são a razão lógica ou a racionalidade estratégica, mas a experiência das situações.

Na sua pedagogia das competências, Ramos (2001) argumentou que a profissão na qualificação possui as dimensões econômica (sobrevivência), sociológica (identidade) e ético-política (regras e valores). São realidades mediadas pela ação pedagógica. As tendências do novo profissionalismo das competências ou a empregabilidade são as exigências psicológico-individuais para a adaptação às mudanças do capitalismo e preparação para a mobilidade e trabalho autônomo.
A metodologia na noção de competência se fundamenta na teoria funcionalista que reforça o irracionalismo pós-moderno, integrando os elementos sociais num contexto equilibrado. No sistema integrado, a importância das pessoas é maior do que seus papéis, bem como seus atributos psicológicos para lidar com a flexibilidade das organizações e com os eventos. A teoria geral dos sistemas adapta o funcionalismo ao contexto econômico-produtivo local.

Para Ramos (2001), no sistemaintegrado e flexível, a importância é conferida mais às pessoas do que aos papéis que elas exercem. As funções são descritas em termos de resultados, que podem ser atingidos por procedimentos diversos, desde que o equilíbrio organizacional seja permanentemente mantido ou recomposto. Mas a pessoa que interessa é a pessoa funcional, isto é, aquela que mobiliza seus atributos cognitivos e socioafetivos para obter os resultados esperados. Os atributos psicológicos dos indivíduos assumem importância para o funcionamento integrado eflexível das organizações. A competência configura-se como uma noção adaptadora do comportamento humano à realidade contemporânea.

A atuação profissional em turismo possibilitaria enriquecimento das competências com as aptidões dos saberes técnicos, o savoir-faire que se adquire no local de trabalho. O profissional que atua em algum segmento do sistema de turismo (SISTUR) teria maiores oportunidades de desenvolver competências. Mesmo atuando, por exemplo, como garçom ou recepcionista, o profissional de turismo estaria inserido em um ambiente de comunicação com públicos diversos e exigência de conhecimentos de aspectos culturais e econômicos. Demandas heterogêneas e tipos diversificados de ofertas de atrativos, sazonalidade e organização de eventos proporcionam aquisição de experiências de situações que transcendem a racionalização lógica para abranger a racionalidade estratégica.

Sob o enfoque da qualificação, o profissional do turismo possui as dimensões econômica, sociológica e ético-política. As exigências das tendências profissionais das competências do modelo flexível ou toyotista estão presentes no turismo: atributos psicológicos para adaptação às mudanças do capitalismo e mobilidade no trabalho autônomo, em razão da diversidade de segmentos do setor e da heterogeneidade da demanda. Quanto à metodologia na noção de competência, a teoria funcionalista se aplica na gestão do turismo como sistema - sistema de turismo ou SISTUR. Há grande exigência de manter o equilíbrio do sistema, formado por uma rede de organizações. Enfatiza-se, no turismo, a importância das pessoas, pois há uma relação mais constante e direta entre o profissional e o cliente. A organização e a gestão de eventos como atrativos e estratégias inovadoras exigem muita flexibilidade dos profissionais. O funcionalismo que enfatiza os atributos subjetivos é adequado pela teoria geral dos sistemas (SISTUR) ao contexto econômico-produtivo do turismo. 
Por isso, a lógica da competência não se limita a propor que a escola promova o desenvolvimento de competências para a atuação autônoma e responsável na vida ativa, mas prescreve, em certa medida, que competências devem ser estas, associadas às diferentes esferas de atividades: técnico-profissional, econômica, social, política e cultural (Ramos, 2001).

Uma destas esferas de atividades é o turismo. E uma das orientações e práticas pedagógicas que se enfatizam no ensino do turismo é a articulação de diferentes conhecimentos teórico-práticos para a construção da formação profissional. Esta articulação, entendida como interdisciplinaridade, é o processo que envolve a integração de educadores para interação entre si e com a realidade, objetivando a formação integral dos alunos, mediante uma visão ampla do mundo e dos problemas (Lück, 1994). Pela dinâmica de sua organização, o turismo é ligado a quase todos os setores da vida social humana, devendo ser ministrado em forma de rede, pois é produtor de múltiplas inter-relações que se desdobram (Beni, 2000). Verifica-se que a prática pedagógica do turismo, em poucos casos, contempla a interatividade das disciplinas e conteúdos programáticos (Nascimento, 2002). É necessária, portanto, uma maior interação entre os processos educativo e administrativo do turismo, integrando-os ao ambiente externo e acompanhando os processos de mudança (Ruschmann, 2002).

\section{Políticas de ensino em turismo}

As políticas de educação profissional, tanto na escola quanto na empresa, estão relacionadas com os processos de transformação da sociedade do trabalho. As mudanças do mercado de trabalho e suas implicações na formação profissional decorrem da evolução do sistema capitalista de produção, por meio dos modelos taylorista, fordista, neofordista e flexível. No aprofundamento da análise sobre a formação profissional, talvez a teoria marxiana proporcione mais respostas, tendo em vista uma inserção mais justa e igualitária da classe trabalhadora, tanto na própria formação quanto no mercado de trabalho. Esta teoria seria, entretanto, inviável na prática, isto é, a implementação das idéias e propostas em sua integralidade seria utópica.

De acordo com as referências curriculares da educação profissional de nível técnico do MEC - Ministério da Educação e Cultura (Brasil, 2000), o mercado de trabalho vem se reconfigurando e colocando novas exigências para os profissionais da área de turismo e hospitalidade. Enfatiza-se a necessidade da valorização da educação geral, na medida em que ela é condição essencial para todo desempenho técnico-profissional frente aos novos paradigmas econômico-sociais. Passa a ser requerido o desenvolvimento das competências de comunicação e de conhecimentos científicos e socioculturais, próprias da educação básica: atributos de raciocínio e expressão lógicos; de comunicação oral, escrita, simbólica, interpessoal e grupal; de autonomia, iniciativa, criatividade, cooperação, solução de problemas e tomada de decisões.

As qualificações profissionais devem corresponder a ocupações existentes no mercado de trabalho e requerem que a habilitação, como processo educacional de formação atualizado, seja capaz de gerar a desejada laboralidade ou empregabilidade dos egressos. Assim, o profissional de nível técnico em turismo e hospitalidade, para atender às exigências requeridas pelo mercado de trabalho, deverá, no curso de nível técnico, receber: (1) formação para constituição de competências gerais que lhe permitam ganhar flexibilidade e versatilidade, visando a acompanhar as transformações do mercado de trabalho; (2) formação que desenvolva competências específicas que atendam às demandas constatadas.

Nas indicações do MEC para itinerários formativos, o aluno deverá cursar um módulo introdutório e módulos de qualificação integrantes, a fim de obter o certificado de qualificação profissional. Caso o aluno tenha concluído também o ensino médio, receberá o respectivo diploma de técnico em serviços de turismo ou de técnico em serviços de hospitalidade. Se necessárias e adequadas para atender a demandas específicas locais ou regionais, habilitações ainda mais segmentadas e diferenciadas podem ser desenhadas, como, por exemplo, de técnico em agência de ecoturismo ou em hospedagem em colônia de férias, ou em alimentação de coletividades. Existe, ainda, o entendimento e a aceitação geral de que uma efetiva profissionalização está baseada em uma educação básica de boa qualidade, requisito que deve ser atendido pela área de turismo e hospitalidade, uma vez que ele abrange muitos outros setores econômicos e múltiplos bens, serviços e conhecimentos de várias áreas da atividade humana.

As referências curriculares da educação profissional do MEC ressaltam que o setor de turismo implica preponderantemente o relacionamento do profissional com outro ser humano, e não com uma máquina ou com insumos, como ocorre com trabalhadores de outros setores da economia. Decorre daí a importância da capacidade de comunicação sob todas as formas, desde a lingüística e interpessoal até a tecnológica. A área de turismo e hospitalidade está mais acentuadamente centrada nos eixos da gestão e da comunicação, pela natureza das atividades que seus profissionais desenvolvem no processo de concepção, criação, planejamento, venda e administração da execução dos serviços aos clientes.

A •IT - Organização Internacional do Trabalho realizou, de 1974 a 1991, várias reuniões técnicas, cuja pauta tratou de questões ligadas ao turismo e que 
resultaram em documentos que assinalam as tendências para a área: (a) o crescimento continuado do fenômeno turístico; (b) sua internacionalização; (c) sua independência em relação às crises mundiais. Em meio a este cenário de tendências e desafios, a OIT identifica que os profissionais da área devem possuir atributos, como polivalência, mobilidade, disponibilidade, capacidade de comunicação, animação e integração em equipe. Para a ênfase a tais competências e atitudes, supõe-se que o profissional possua uma boa, ampla e aberta cultura geral e humana, um conjunto de conhecimentos teóricos e práticos e uma personalidade, ao mesmo tempo, firme e flexível para lidar com os problemas sociais e as situações do emprego nos hotéis, restaurantes e estabelecimentos similares.

\section{A oferta da educação profissional em turismo}

Em nível básico, os cursos de qualificação para os serviços em turismo e hotelaria oferecidos, no Brasil, são os seguintes: emissão de passagens, turismo para taxistas, qualidade no atendimento, recepcionistas e camareiras, cozinheiro e garçom. Estes cursos são ministrados pelo SENAC - Serviço Nacional de Aprendizagem Comercial, nos seus centros, empresas, unidades móveis, restaurantes e hotéis-escola; por entidades da classe trabalhadora (sindicatos e associações); instituições que participam dos programas de qualificação e requalificação profissional financiados pelo FAT - Fundo de Amparo ao Trabalhador, vinculado ao Ministério do Trabalho e Emprego.

Em nível técnico, a oferta de cursos é mais reduzida. As iniciativas relativas à hospitalidade restringem-se ao SENAC e às escolas técnicas federais - CEFETs. Só a partir de 1998 começaram a surgir outras iniciativas, inclusive, de escolas públicas estaduais. Os cursos técnicos de turismo são herdeiros da profissionalização obrigatória, imposta pela Lei Federal no 5.692/72, implantados quase sempre pela facilidade e pelo baixo custo. Esses cursos, em sua maioria, não possuem laboratórios ou ambientes especiais, nem recursos tecnológicos, nem biblioteca especializada,e são distanciados do processo produtivo da área, de sorte que seus docentes muitas vezes não têm experiência ou efetiva atuação no mercado de trabalho.

Em razão disso, as grandes e médias empresas da área têm procurado suprir suas necessidades de profissionais formando-os internamente, por meio de programas de treinamento de seu pessoal, programas contratados por terceiros ou desenvolvidos por funcionários preparados para serem também instrutores ou orientadores do desenvolvimento de novos profissionais. Muitos dos profissionais competentes não receberam formação institucionalizada, ou, quando receberam, não a reconhecem como decisiva ou significativa para a qualidade de seus desempenhos profissionais. Contraditoriamente, há uma valorização, pelo menos formal, da boa educação profissional, que poderia e deveria ser oferecida em sintonia com a realidade e as necessidades da área.

O nível superior vem apresentando alto incremento, tanto para os cursos de turismo (bacharelado) quanto de hotelaria (tecnologia e bacharelado), sobretudo pelas instituições particulares, com significativa presença do SENAC e de instituições federais e estaduais de ensino superior. Para Rejowski (2001), no contexto do ensino em turismo, têm-se o ensino livre, o técnico e o superior. Os cursos de graduação podem formar tecnólogos ou bacharéis. A formação de tecnólogos pode ser em hotelaria, turismo ou em gastronomia. A formação de bacharéis se dá por meio de cursos superiores regulares. Mesmo que o país ainda não esteja entre os principais pólos ou destinos turísticos do mundo, apesar de seu extraordinário potencial, a educação em turismo tem-se especializado ao longo das últimas três décadas no Brasil. Novos cursos foram criados em várias áreas e em vários níveis. Em nível superior, tem havido uma focalização dos cursos de administração para o turismo e a expansão dos cursos de hotelaria.

Quanto aos cursos de graduação em turismo e hotelaria, os dados levantados em 2000 indicam que há um total de 298, sendo 204 de turismo, 21 de hotelaria, 9 de turismo e hotelaria e 64 cursos de administração com habilitações na área. De um lado, frente a tal quadro, alguns questionamentos que se impõem são: os formados serão absorvidos pelo mercado de trabalho ou terão condições de montar seus próprios empreendimentos turísticos? Qual é a qualidade da formação superior na área?

De outro, o amadurecimento dos cursos de turismo e sua expansão fora das capitais provocou o aparecimento de propostas diferenciadas, adaptadas ou direcionadas às necessidades e realidades locais e regionais, ao lado de propostas incoerentes, inconsistentes e mal formuladas. Pouco adianta dispor de atrativos turísticos ímpares se, por exemplo, o atendimento nos meios de hospedagem for de regular a ruim, se não houver guias nos monumentos históricos, se os garçons de restaurantes forem impacientes e desatentos, se o motorista de táxi não souber a história e os principais atrativos da cidade, se, nos órgãos públicos, não houver informações turísticas ou, se, ainda, a própria população local não valorizar o seu patrimônio natural e cultural. E, não se deve esquecer que de outro lado, faltam pesquisadores para desenvolver pesquisas básicas e aplicadas à resolução de variados problemas, faltam planejadores e gestores do desenvolvimento turístico, enfim, faltam recursos humanos qualificados e capacitados (Rejowski, 2001).

Um estudo sobre educação e capacitação para carreiras na indústria de viagens e turismo da América Latina, do World Travel \& Tourism Council e da American Express Company, intitulado Profissões para o milênio, também apresenta 
informaçōes significativas para uma visão das necessidades de formação, mais diretamente do ponto de vista das empresas. A questão é tratada sob dois enfoques: da dificuldade no recrutamento de pessoal e da capacitação patrocinada pelas empresas. Pelo enfoque das dificuldades no recrutamento de pessoal competente, as empresas assinalam que são maiores para os níveis de direção e de técnicos qualificados. Foram apontadas dificuldades médias para o nível de profissionais de supervisão e poucas para o pessoal não-qualificado. Pelo enfoque da capacitação patrocinada pelas empresas, o estudo identificou, nos gerentes, ênfase de desenvolvimento das habilidades em computação, atendimento ao cliente, marketing, liderança, línguas estrangeiras, solução de problemas e relaçōes interpessoais.

O SEBRAE-RS - Serviço Brasileiro de Apoio às Micro e Pequenas Empresas do Rio Grande do Sul possui oito comitês setoriais, dentre os quais um comitê de turismo. O SEBRAE-RS vem atuando junto a diversas comunidades regionais do Estado, na implementação de projetos de desenvolvimento do turismo, tais como: Rota Missōes, Atuasserra (Rota da Uva e do Vinho), Veraneio na Serra Gaúcha (Rota das Hortênsias), Quarta Colônia (Região Central), Costa Doce (Metade Sul) e Rota dos Tropeiros (Campos de Cima da Serra). A instituição possui 120 consultores habilitados para atendimento às micro e pequenas empresas do setor e aos municípios, tendo em vista a realização de inventários, diagnósticos, planejamento de marketing, formatação de roteiros, organização de atrativos culturais e museus, entre outras. Os cursos de capacitação - Qualidade do Atendimento Turístico, Turismo com Qualidade, Comercializando o Produto Turístico e Turismo no Meio Rural - têm, em média, 20 horas de duração, são dirigidos a efetivos e potenciais empreendedores, e ministrados por consultores especializados.

\section{Considerações finais}

A escola se depara, atualmente, com o conflito, a dúvida e a incerteza da adequação da formação ao mercado de trabalho. A grande questão é se a diplomação assegura a empregabilidade estável, digna e compensadora, perante um mercado em constante mutação e instabilidade, que impõe uma ressignificação dos currículos e métodos de ensino. Atualmente, são muitos os que exercem atividade sem relação com as qualificações adquiridas na escola. O conceito de educação e formação como garantias de emprego está ultrapassado, e a situação de angústia se agrava pela estagnação da economia, cujos índices de desenvolvimento têm sido pífios e desanimadores. A reconstrução da relação entre educação e mercado de trabalho torna-se, portanto, um desafio cada vez mais complexo para a escola, numa época em que a formação, apesar de ser um fator favorável e vantajoso no processo de inserção profissional, não é mais determinante.
Apesar disto, quanto à questão da criação de mercados pela formação em turismo - criam-se mercados pela formação? -, pode-se inferir que a resposta seja afirmativa, pois as informaçōes e os conhecimentos sobre as evoluçōes do setor podem motivar a busca de aproveitamento das oportunidades que surgem. Haveria um aumento da mobilidade de pessoas já empregadas, constituindo-se em fator de abertura de vagas de trabalho em outras áreas. Pequenos empreendedores ou investidores se motivariam a criar novos negócios no turismo ou diversificar suas atividades. A formação profissional em turismo, por meio da educação institucional ou escolar, incentivaria a criatividade na prospecção de atividades culturais, envolvendo a preservação do patrimônio histórico, o fomento do lazer cultural com a dinamização de museus e a produção de artesanato. $\mathrm{O}$ fortalecimento das manifestaçōes culturais, como bens de valor econômico, e o aumento da autoestima, especialmente, das comunidades do meio rural, são conquistas que a educação em turismo pode proporcionar.

A análise de uma experiência de realização de cursos de formação de guias de turismo, no município de Caxias do Sul, atendendo a uma demanda da região da Serra Gaúcha, comprova que a oportunidade de adquirir e construir conhecimentos e formação criou espaços profissionais para vários participantes. O curso formou a primeira turma em 1987, possibilitando que, após 150 horas de aula, conforme exigência da EMBRATUR na época, 43 alunos obtivessem certificado para regulamentação da atuação profissional. Posteriormente, o curso ampliou, por exigência legal, a carga horária para 400 horas, e, nas demais turmas, de 1988 a 1996, a maioria dos 25 alunos, em média, não atuava como guia e buscava oportunidade no mercado. Vários egressos passaram a atuar efetivamente como guias, outros se estabeleceram como agentes de viagens, e alguns obtiveram oportunidades de trabalho nos segmentos de hospedagem e alimentação. O curso ensejou, ainda, que professores de nível médio adquirissem conhecimentos de turismo e se tornassem professores nesta área, com a agregação de técnicas e competências didático-pedagógicas.

Constata-se, pelos exemplos de casos analisados - pesquisa sobre o mercado de trabalho em Curitiba, o estudo do World Travel \& Tourism Council, atuação do IH (Instituto de Hospitalidade) e cursos de formação de guias de turismo na Serra Gaúcha -, que um dos requisitos do desenvolvimento do turismo é que haja uma adequada preparação da oferta de serviços turísticos e, também, da demanda por turismo. Esta preparação seria muito mais produtiva e exitosa por meio da formação. Em razão de se diferenciar dos demais setores da economia, pela diversidade e abrangência de tipos de oferta de segmentos que abrange, constituindo-se em um sistema (SISTUR), a atuação em turismo requer múltiplas formaçōes, reunidas em um mesmo profissional, ou dos mais diversos profissionais 
que integram os segmentos da cadeia produtiva. Assim, a formação nas áreas de cultura, hospedagem, alimentação e comércio são fundamentais para o sucesso do mercado do turismo. Da mesma forma, para motivar a demanda por serviços ou produtos turísticos, é necessária a atuação de bons profissionais de marketing e comunicação. É importante salientar que, no caso do planejamento de marketing, o turismo apresenta peculiaridades especiais que requerem uma orientação que privilegie tanto a comunidade receptora quanto os clientes visitantes.

O desenvolvimento do turismo depende da adequada gestão municipal da qualidade dos meios receptores urbano e rural. No meio urbano, são essenciais a preservação e a revitalização do patrimônio histórico (prédios, monumentos, museus), dos parques e praças. Ainda que muitas ações sejam implementadas de forma isolada, o turismo pode contar com atuação de profissionais das áreas diversas, como arquitetura, meio ambiente, cultura, museologia, organização de eventos, guias e artistas. O papel dos gestores é articular os vários segmentos para o planejamento e a construção de um ambiente agradável, proporcionando bemestar para que a comunidade seja feliz e tenha condições de proporcionar hospitalidade aos turistas visitantes. O retorno, portanto, de investimentos realizados nas áreas de arte, antropologia e história podem ser viabilizados pelo turismo, pois ele transforma bens, aparentemente de pouco valor, em patrimônios de grande valor econômico-cultural.

Para isto, é necessário que tanto os gestores do turismo municipal quanto os profissionais das diversas áreas envolvidas possuam competências que podem ser aprimoradas pela experiência da atuação prática, mas que são resultados de conhecimentos teóricos e de aprendizado adquiridos em sala de aula. Além disto, características e peculiaridades da gestão e do controle do turismo por meio de modelos teóricos, como sistema, cadeias produtivas, alianças estratégicas, redes de cooperação e de conceitos como sustentabilidade e heterogeneidade da demanda, são saberes adquiridos na escola.

O fato de a maioria dos empregos gerados nos serviços relacionados ao turismo ser relativamente de baixa capacitação significa que o turismo é um dos poucos setores que possibilita que pessoas de baixa capacitação profissional sejam inseridas no contexto do trabalho. Ainda que esta inserção não se efetive da forma justa como deveria, é uma maneira de proporcionar experiência e conhecimento, especialmente para as pessoas que procuram uma oportunidade de trabalho pela primeira vez e que podem, com isto, galgar posições mais compensadoras no futuro. Além disto, Urry (2000) admitiu que o turismo é uma das poucas alternativas como estratégia de desenvolvimento para os países emergentes.

No caso do turismo, vale a mesma argumentação quanto ao aproveitamento de pessoas de baixa capacitação para o trabalho nas demais atividades. Por tratar-se de uma atividade sazonal, pois depende de condições como clima e disponibilidade de tempo para férias, geram-se demandas por trabalho temporário, nas estações de alta temporada. Muitos destes trabalhos viabilizam-se na informalidade. É preferível, portanto, que existam oportunidades de trabalho, ainda que informais e não adequadamente remuneradas, à inexistência de qualquer oportunidade para a aquisição de competências de saber fazer e saber ser, que podem impulsionar a conquista de patamares mais compensadores de atuação profissional.

Isso não significa que se deva concordar ou aceitar esta situação como normal e irreversível, mas que seja considerada como uma etapa importante do processo de inclusão de mais pessoas na sociedade do trabalho. Assim como em outras atividades econômicas, no turismo existem empresas que atuam em caráter de informalidade, e esta é uma questão conjuntural que precisa ser analisada sob os critérios da justiça social e da dignidade da sobrevivência humana. Pode ser moralmente mais aceitável que se tolere a sobrevivência na informalidade do que a pobreza e a indigência dos excluídos pela inépcia e pela omissão das instituições responsáveis.

O conceito de empregabilidade está intimamente ligado à noção de competência. O desafio da escola é preparar o indivíduo para a instabilidade, inclusive para o desemprego e para ser agente de mudança. O discernimento do real papel e da responsabilidade da escola, em meio a esta reviravolta metodológica, impõe-se num momento em que, conforme argumentou Stroobants (1997):

[...] a mensagem geral é que as competências no trabalho seriam mais importantes do que se acreditava. Estas competências, supostamente mais reais do que as capacidades oficialmente reconhecidas, mais eficazes do que os saberes formais, definem-se também por oposição aos saberes escolares. Estes saberes tácitos não parecem poder ser adquiridos de outra forma senão no local de trabalho.

Este local de trabalho pode ser um dos segmentos do turismo, ainda que, em um primeiro momento, seja de maneira informal e precária.

Agradecimentos ao professor-doutor Jorge Alberto Rosa Ribeiro,

do Programa de Pós-graduação em Educação (PPGEDU) da Universidade Federal do Rio

Grande do Sul (UFRGS), e à professora-doutora Mirian Rejowski, diretora-presidente da Associação Nacional de Pesquisa e Pós-graduação em Turismo (ANPTUR). 


\section{Referência bibliográficas}

BATESON, John \& HOFFMAN, Douglas. 2001. Marketing de serviços. São Paulo: Artmed.

BENI, Mário Carlos. 2001. Globalização do turismo: megatendências do setor e a realidade brasileira. São Paulo: Aleph.

BOYER, Robert. 1986. La flexibilidad del trabajo em Europa. Madrid: MTTS.

BRASIL. Ministério da Educação. 2000. Área profissional: turismo e hospitalidade. Educação profissional - Referências curriculares nacionais da educação profissional de nivel técnico. Brasília.

CARLZON, Jan. 1994. A hora da verdade. Rio de Janeiro: COP.

CASTELLS, Manuel. 1999. A sociedade em rede. São Paulo: Paz e Terra.

DE MASI, Domenico. 2000. O ócio criativo. Rio de Janeiro: Sextante.

DELUIZ, Neise. 2001. O modelo das competências profissionais no mundo do trabalho e na educação; implicaçōes para o currículo. Boletim Técnico do SENAC, Rio de Janeiro v. 27, n. 3, set./dez.

FITZSIMMONS, James \& Mona. 2000. Administração de serviços. Porto Alegre: Bookman.

GANDARA, José M. LUKE, Otto \& PAIXĀO, Luiz D. 2003. Empregabilidade nas empresas turísticas, um estudo do mercado hoteleiro de Curitiba. Caxias do Sul - UCS: I Seminário de Turismo.

KRIPPENDORF, Jost. 1989. Sociologia do turismo. Rio de Janeiro: Civilização Brasileira.

LÜCK, Heloísa. 1994. Pedagogia interdisciplinar: fundamentos teórico-metodológicos. Petrópolis: Vozes. MOESCH, Marutschka. 2000. A produção do saber turístico. São Paulo: Contexto.

MOLINA, Sergio. 2003. O pós-turismo. São Paulo: Aleph.

POCHMANN, Márcio. 1999. O trabalho sob fogo cruzado. Campinas: Contexto. 2001. A década dos mitos. Campinas: Contexto.

OLIVEIRA, Luísa. 1998. Inserção profissional. Lisboa: Cosmos.

RAMOS, Marise Nogueira. 2001. A pedagogia das competências: autonomia ou adaptação? São Paulo: Cortez.

RIBEIRO, Jorge A. Rosa. 2000. Emprego assalariado, qualificação e mercados de trabalho. Tesis Doctoral. Salamanca: Universidad de Salamanca. (Cap. 4, p. 147-182).

REJOWSKI, Mirian. 2001. Ensino em turismo no Brasil: reflexōes sobre a realidade do ensino de graduação de 1970 a 2000. Caxias do Sul: EDUCS.

RODRIGUES, Adyr. 1999. Turismo e espaço: rumo a um conhecimento transdisciplinar. São Paulo: Hucitec.

RUSCHMANN. Dóris. 2002. Turismo no Brasil: análise e tendências. Barueri: Manole.

SEBRAE-RS - Serviço Brasileiro de Apoio às Micro e Pequenas Empresas. Porto Alegre, 2003.

SINGER, Paul. 1998. Globalização e desemprego, diagnóstico e alternativas. São Paulo: Contexto.

STROOBANTS, Marcelle. 1994. A visibilidade das competências. Campinas: Papirus.

THURROW, Lester. 1997. O futuro do capitalismo. Rio de Janeiro: Atlas.

URRY, John. 2000. The tourism gaze. London: Sage.

VILLA, Paola. 1990. La estruturación de los mercados de trabajo. Madrid: Ministerio de Trabajo.

\section{Sites da Internet}

www.abih.com.br - Associação Brasileira da Indústria de Hotéis. www.embratur.gov.br - EMBRATUR - Instituto Brasileiro de Turismo. www.estudosturisticos.com.br - Ministério do Turismo do Brasil. www.hospitalidade.org.br - Instituto de Hospitalidade.

www.sebrae-rs.com.br - Serviço Brasileiro de Apoio às Micro e Pequenas Empresas - RS. www.world-tourism.org - Organização Mundial do Turismo. www.wttc.org - World Travel and Tourism Council.

Recebido em: 28/11/2006.

Aprovado em: 18/01/2007. 